\title{
Framing gender equality \\ Message guide
}

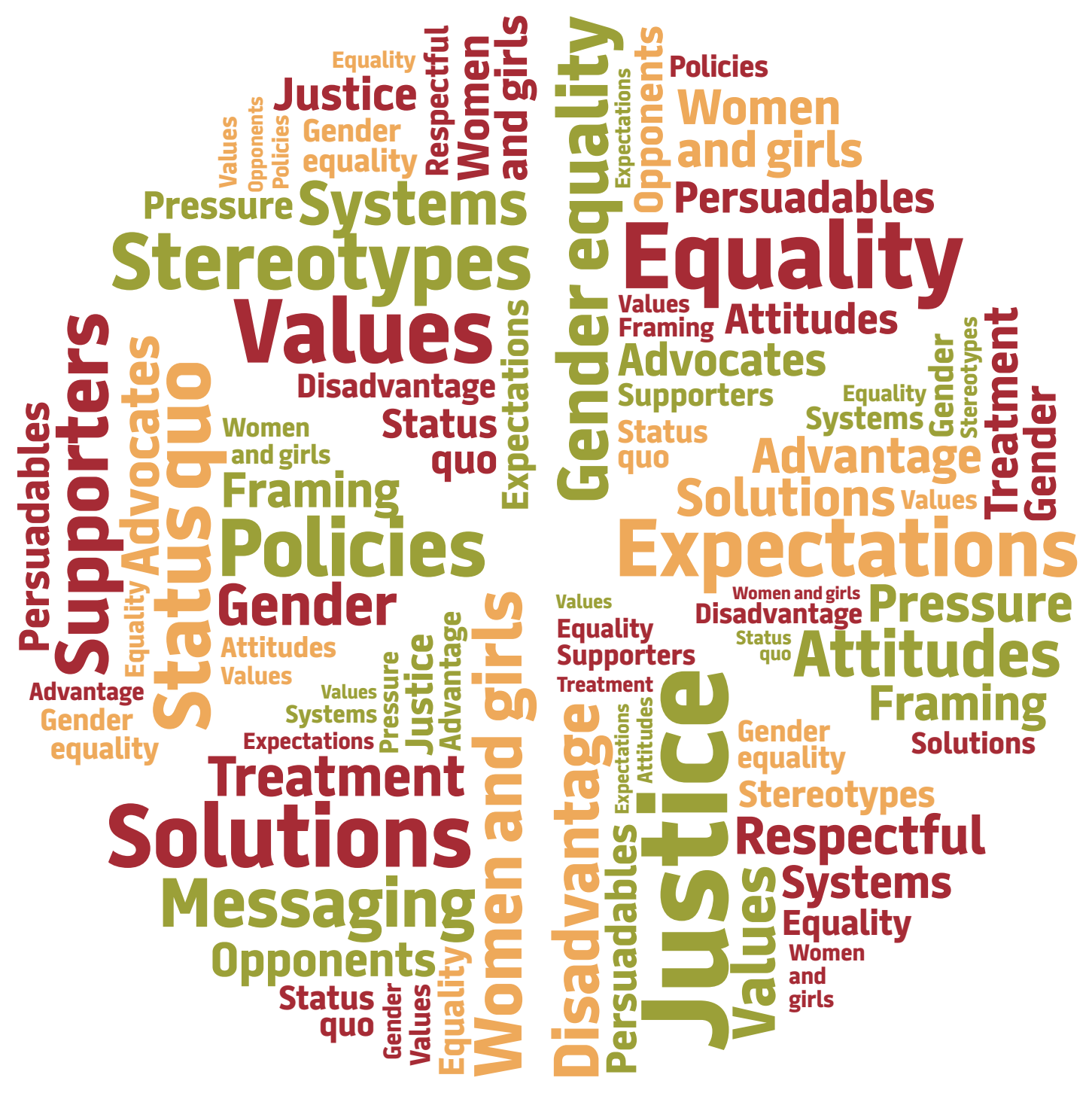


This messaging guide contains recommendations that will help you boost support for gender equality initiatives in Australia. It is based on extensive research undertaken by Common Cause Australia on behalf of VicHealth and the Together for Equality and Respect Partnership with the support of the Outer East Primary Care Partnership.

We envisage the primary users of this guide will be people working to create a more equal and just society for women and girls. This includes those seeking to build greater public support for systemic solutions to gender inequality through policy and organisational change as well as those working on individual behaviour change initiatives. 


\section{Contents}

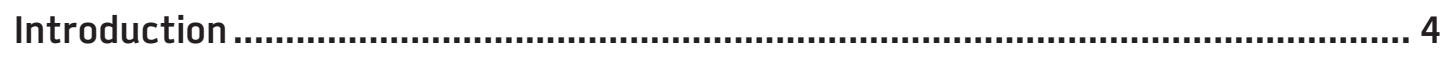

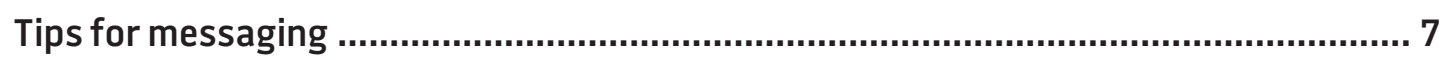

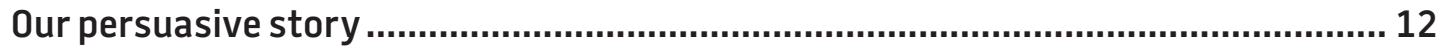

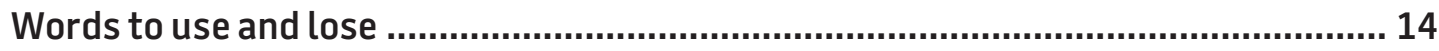

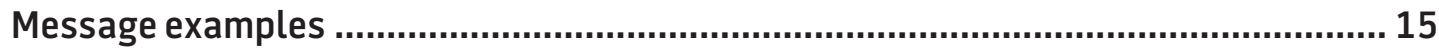




\section{Introduction}

\section{Approach}

The research and recommendations outlined in this guide are based on the Common Cause approach to community engagement. This approach is based on decades of research from the fields of social psychology, cognitive linguistics and behavioural economics.

A key finding of this research is that most people think about social issues from multiple and often conflicting perspectives. Importantly, these different perspectives operate mostly at a subconscious and emotive level, which means people's attitudes and behaviours are often driven by factors beyond their conscious awareness.

In our research on gender equality messaging, we sought to identify perspectives (also known as frames) which make people feel at a gut level that gender equality initiatives are both valuable and necessary. We also sought to understand which frames moved people into an oppositional mindset in which gender equality initiatives feel unnecessary or harmful. Identifying these oppositional frames is just as important as supportive frames, because it tells us which ideas we should avoid activating in our audiences.

\section{"Messages that appealed strongly to supporters and also shifted persuadables were identified as most useful for future messaging."}

\section{Methodology}

In order to identify the dominant frames that people in Australia use to think and talk about gender equality, we conducted a national public discourse analysis. This involved collecting and coding over 20,000 words of language data from dozens of publicly available sources of discourse on the topic of gender equality - including media articles, opinion pieces, political debates, social media discussions and popular culture.

In addition, we conducted 15 confidential one-on-one interviews with key advocates for gender equality in Australia. This language data was then coded and analysed based on key metaphors, values and story logic in order to identify the dominant supportive and oppositional frames used by Australians to think and talk about the topic.

These findings were then tested using an online survey of more than 1,800 Australians ${ }^{1}$. The 15-minute survey included a range of question formats - including forced choice ${ }^{2}$ and split sample ${ }^{3}$ questions. We also tested five 30 -second audio-recorded messages ${ }^{4}$ in which participants moved a dial up and down on their screens as they listened to the messages to indicate their level of agreement with what they were hearing in that moment. This provided us with a moment-by-moment view of the persuasive effect of the messages we tested and allowed us to isolate specific words and phrases that most resonated with audiences.

\footnotetext{
1 The sample of 1,817 respondents was drawn from an existing national panel and are weighted to be geographically representative of the Australian population.

${ }^{2}$ Forced choice questions force respondents to choose between one of two statements with no option to skip or opt out of the question. This allows us to assess the strength of opposing frames relative to each other - for example, to assess whether a promising advocate message is more or less powerful than a common opposition message.

${ }^{3}$ Split sample questions split the entire sample into two random groups and present each with different versions of the question. These questions are used to assess the impact of using different words or frames on people's responses.

${ }^{4}$ All audio-messages featured the same male voice. It is possible that a female voice could have resulted in difference responses. This is something future research could explore.
} 


\section{Attitudinal Groups}

By scoring survey respondents' answers to key questions throughout the survey, we were able to identify three attitudinal groups on the topic of gender equality:

\section{Our research identified three key attitudinal groups on the topic of gender equality}

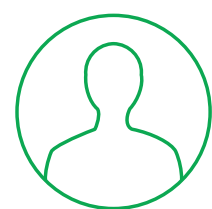

Supporters

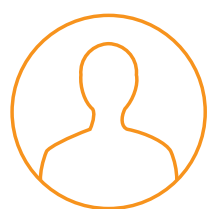

Persuadables

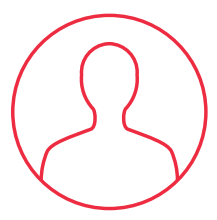

Opponents
- Supporters: people who strongly believe gender inequality is a problem in Australia and support the full range of solutions required to address it.

- Persuadables: people who hold conflicting attitudes towards gender equality and move between oppositional and supporter perspectives on the issue.

- Opponents: people who consistently deny gender inequality is a problem in Australia and strongly oppose any systemic solutions.

We analysed the full results of the survey based on the responses of these three groups to each of the questions and messages.
Messages that appealed strongly to supporters and also shifted persuadables were identified as most useful for future messaging. These are messages that move persuadables into a supporter mindset. On the flip side, messages that appealed strongly to both opponents and persuadables were identified as harmful messages because they move the latter into an oppositional frame of mind.

Encouragingly, our survey found a quarter of respondents (25\%) are supporters, while only $15 \%$ of were entrenched opponents. Meanwhile, almost two in three people (60\%) were persuadable on the topic and toggle between supportive and oppositional attitudes towards gender equality.

As the table below illustrates, the gender people identify with strongly influences their likelihood of being opponents or supporters. There are almost three times as many men who are opponents of gender equality than women. Meanwhile, women are twice as likely as men to be supporters. However, it's worth noting the majority of both women and men in Australia are persuadable on the topic and, as such, their level of support or opposition to gender equality initiatives depends on how the issue is framed.

\section{Supporter Persuadable Opposition}

\begin{tabular}{lccc} 
Women & $33 \%$ & $\mathbf{5 9 \%}$ & $\mathbf{8 \%}$ \\
\hdashline Men & $16 \%$ & $\mathbf{6 2 \%}$ & $\mathbf{2 2 \%}$ \\
\hdashline Total & $25 \%$ & $60 \%$ & $15 \%$ \\
\hline
\end{tabular}

In the area of gender equality, our survey showed the following:

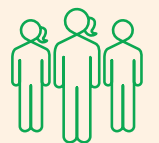

SUPPORTERS

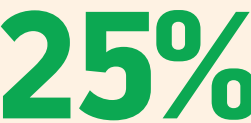

of the population are supporters of gender equality

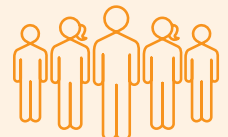

PERSUADABLES

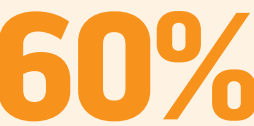

of the population hold conflicting and/or weak attitudes towards gender equality

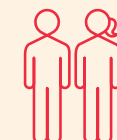

OPPONENTS

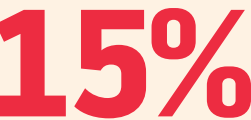

of the population does not support gender equality 


\section{Geographic samples}

To explore how attitudes to gender equality differed geographically, we also surveyed 326 people living in the Eastern Metropolitan Region of Melbourne and 308 people living in regional Victoria ${ }^{5}$. We then analysed how their responses differed compared with the national panel.

Overall, we found attitudes to gender equality in the Eastern Metropolitan Region were slightly more progressive than the national average with higher levels of agreement that gender inequality is an ongoing problem and greater support for gender equality policy and initiatives. That said, the difference in the way this cohort responded to our messages was typically only a few percentage points beyond the margin of error and not suggestive that a radically different approach to messaging is called for in this region.

Meanwhile, in analysing responses from men and women in regional Victoria we found very little differences in attitudes and responses to messaging compared with respondents living in metro areas of Victoria. We also compared responses from regional areas across Australia and compared these with national metro respondents and, again, failed to identify statistically significant differences that amounted to any clear pattern. This may, in part, be due to the difficulty of achieving a truly representative sample of respondents in regional areas using an online survey. But it may also suggest that when it comes to persuading people of the importance of gender equality, geography is less important than other demographic variables - including gender, education and political orientation.

\section{Our research suggests the majority of people in both metropolitan and regional areas are persuadable when it comes to gender equality.}

\begin{abstract}
In any case, our research suggests the majority of people in both metropolitan and regional areas are persuadable when it comes to gender equality. Across the Eastern Metropolitan Region 58\% of respondents were identified as persuadable, while in regional areas they represented $60 \%$ of respondents. No matter where they live, these are the people we need to influence if we want to boost support for gender equality in Australia. Indeed, it is this persuadable group of people that the recommendations in this guide are primarily aimed at influencing.
\end{abstract}




\section{Tips for Messaging}

The following are evidence-based tips for telling a more persuasive story about gender equality in Australia.

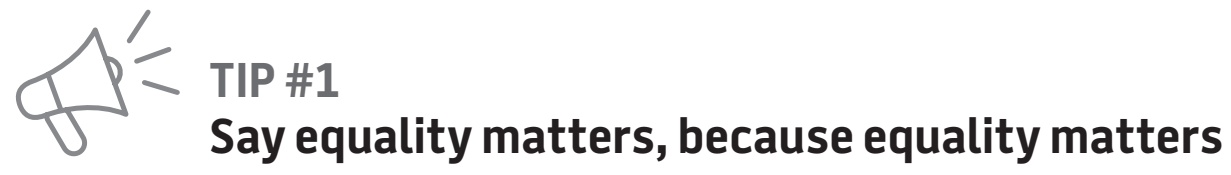

\footnotetext{
Advocates for gender equality frequently justify their initiatives on the basis that creating a more gender equal society will benefit everyone. In many cases this involves framing gender equality as a way to boost the overall economy or the performance of individual businesses. At other times, advocates simply point out that gender equality 'benefits everyone', without providing specific details.

While all this is true, framing our work in this way implies equality for women and girls is only a means to an end and not something that matters for its own sake. When we say it 'benefits everyone', we're really pointing out it also benefits men and boys. The assumption is that unless we point out the additional benefits of women being equal to men, our community will not support our work.

Our research suggests the opposite. Not only did we find high levels of support for messages that framed the issue clearly in terms of equality and freedom for women and girls, but also that framing the issue as 'benefitting everyone' actually reduced levels of support from persuadable audiences including men.
}

For example, more people agreed with the statement "Government should do more to address gender inequality because women and girls deserve to be treated as equals" than agreed with "Government should do more to address gender inequality because it will benefit everyone". In fact, even men responded better to government intervention when the issue was framed in terms of equality as opposed to mutual benefit.

Indeed, across our entire survey, messages that affirmed the values of equality or self-direction for women and girls performed better than anything else we tested. Net agreement levels among persuadables for equality-based vision statements typically hovered around $90 \%$, far higher than even the most persuasive opposition messages.

This doesn't mean you need to ignore the realities of how the status quo also harms men and boys or non-binary people. But when discussing the impacts on men and boys in particular, be careful not to imply that gender equality only matters because it also benefits them.

\section{In short, frame equality for women and girls as important in its own right, rather than something that needs to be justified as benefitting everyone.}

\section{MESSAGE SHIFT}

FROM

Sexual harassment in the workplace costs businesses millions in reduced productivity.

\section{TO}

Businesses have a responsibility to ensure their workplaces are safe places for women to work - free of sexual harassment.
The Gender Equality Act will benefit everyone in Victoria. 


\section{Focus on causation, not just outcomes}

Gender equality advocates often focus on the different economic, social and political outcomes for men and women as proof that change is needed. We point to unequal outcomes such as the 'gender pay gap', or women's underrepresentation in leadership roles, or overrepresentation in unpaid care work and assume this makes a clear case for action.

Unfortunately, simply pointing out that women and men enjoy different outcomes in life does not prove that those outcomes are unjust. In fact, one of the key elements of our opposition's narrative is that women and men are fundamentally different in terms of their interests, skills and abilities. It is, therefore, reasonable, if not inevitable, that they end up with different outcomes in life.

This line of reasoning resonates strongly with persuadable audiences. For example, $78 \%$ of persuadables agree it is natural for men and women to want different things out of life. Similarly, more persuadable people agree than disagree that "women are naturally suited to caring professions while men are more suited to competitive problem-solving roles."

Therefore, when we focus only on different outcomes in life for men and women, this does nothing to challenge the opposition narrative that men and women are fundamentally different.
In fact, it may even strengthen this unhelpful concept by pointing out how men consistently do better in business and politics, while women continue to dedicate more of their time to caring for others.

However, when we focus instead on unequal expectations, pressures and treatment of people based on gender, we shift persuadable audiences into a strongly supportive mindset.

For example, among persuadable audiences, $87 \%$ agreed we shouldn't make assumptions about people based on their gender; $90 \%$ agreed a person's gender should not get in the way of them leading the life they choose; and $78 \%$ said that treating women and girls differently because of their gender is wrong.

Naming specific examples of unequal treatment, meanwhile, generates even higher levels of outrage from persuadable audiences. For example, $90 \%$ agree it's wrong for businesses to pay women less than men for doing the same work and also that it's wrong for women to be overlooked for promotions and pay rises they deserve.

In other words, while persuadable audiences believe it is 'natural' for men and women to want different things out of life, they also believe it's wrong to make assumptions about people based on their gender or to treat them differently as a result.

\section{In short, when framing the problem, focus on unequal expectations, pressures and treatment of people based on gender.}

\section{MESSAGE SHIFT}

FROM

It is wrong for women

to earn less than men

in the tech industry.
To It is wrong for tech companies to pay women less than men for the same work.
Women still do significantly more housework than men in Australia.
T0 Women are more likely to be judged than men for not doing housework and end up doing the majority of it. 
Talk about men's advantage (not just women's disadvantage)

Many advocates are hesitant to mention the ways in which men benefit from the status quo. They fear that doing so will turn off persuadables and activate defensiveness in men.

As a result, when talking about gender inequality, advocates focus overwhelmingly on the disadvantages women face and rarely point out the advantages men enjoy. This frames gender inequality as a women's issue, where the goal is to lift women up to the 'normal' status of men.

In other words, this frames our solutions as charity, rather than justice. Instead of gender equality initiatives being about correcting the unfair way in which men and women are treated in our society, they are framed as extra support for an underachieving group of people. No wonder then, that many end up perceiving gender equality initiatives as unfair - after all, they reason, men didn't receive extra support to get to where they are today.
In fact, in our testing, we found the opposition significantly more comfortable with messages that framed gender inequality in terms of women's disadvantage rather than men's advantage. This suggests that messages focused exclusively on 'women's disadvantages' are not challenging the opposition narrative and may, indeed, be playing to their belief in women's natural inferiority.

Encouragingly, we found no drop-off in support from persuadable audiences when we talked about gender inequality in terms of the advantages flowing to men. This suggests that not only are our supporters comfortable with a more truthful and justice-oriented story around gender equality, but so are the vast majority of Australians.

\section{In short, explain how the current system advantages men at the expense of women to frame your solutions as a matter of justice, not charity.}

\section{MESSAGE SHIFT}

FROM

Women are underrepresented in leadership roles and are more likely to be overlooked for promotions. то Men are overrepresented in leadership roles and are less likely to be overlooked for promotions than women.
The economic stimulus plan does not provide enough support to female dominated industries.
The economic stimulus plan protects industries that employ mostly men, while leaving those that employ more women to fend for themselves. 


\section{Be solutions focused}

Persuadable audiences are significantly more motivated by solution focused messages than those elaborating on the problem. While emphasising the scale of the problem tends to rev-up existing supporters (by reminding them of what they already believe), persuadable people are turned off by negative messaging.

With very few exceptions, we found messages outlining solutions were significantly more effective among persuadable audiences than those articulating the problems these solutions were designed to address. In other words, persuadable people are less likely to agree that there is a problem than they are to support you to fixit.

Logically, this makes no sense. But emotionally it does. It's much easier to ignore a problem, or explain it away, than confront the painful reality of yet another injustice in the world. Solutions, on the other hand, offer hope of a better world, and are met with more openness as a result.

For example, while only half of persuadable audiences agreed that women are still treated differently because of their gender, over two thirds supported more government action to address gender inequality. Similarly, while $60 \%$ of persuadables agreed that men and women still feel pressure to conform to traditional gender roles, $72 \%$ agreed that ending gender stereotypes would lead to benefits for both women and men.

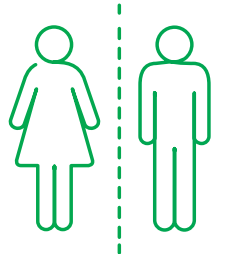

$60 \%$

of persuadables agreed that men and women still feel pressure to conform to traditional gender roles
$72 \%$

agreed that ending gender stereotypes would lead to benefits for both women and men
This doesn't mean you should ignore the problem. An important part of our narrative must be demonstrating the way in which outdated attitudes, behaviours, systems and policies continue to harm women and girls. But if we want to engage people in this narrative, we need to spend far less time elaborating on the problems, and more time showing how we can work together to fix them.

\section{In short, to entice persuadable audiences to engage with your message, spend more time talking about solutions than problems.}

\section{MESSAGE SHIFT}

Gender based pay discrimination

is still a major problem in many

businesses across Australia, leaving female employees short-changed.

Gender pay audits can help
businesses identify and address
discriminatory pay, so women
are equally compensated for
their hard work.




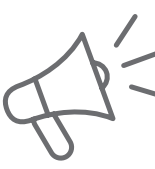

TIP \#5

\section{Stick to your story (instead of mythbusting)}

The entrenched opposition to gender equality in Australia represents just $15 \%$ of the total population. Yet they are a vocal bunch. These are the people you see arguing loudly on social media about the 'feminist war on men' and the injustice of giving 'special privileges to women' while men and boys are increasingly 'discriminated against'.

It's tempting to weigh into these debates and use the wealth of facts at our disposal to show how these ideas are misguided if not outright dangerous. But the evidence on mythbusting shows it does more harm than good. This is because reminding people of unhelpful ideas in an effort to prove they are wrong, only serves to strengthen those ideas further in people's minds. We're effectively forcing our audience to think about the issue from the opposition's perspective.
Unfortunately, mythbusting is a common tactic deployed by many gender equality advocates in Australia. Not only does mythbusting risk toggling our persuadable audiences into an opposition mindset, it is a wasted opportunity to strengthen our persuasive story.

The solution to mythbusting, therefore, is to stop telling your audience what the opposition thinks and start telling them our story instead. This is particularly pertinent given our research shows we have a highly persuasive story at our disposal.

\section{In short, stop telling your audience how not to think about gender equality and start telling them your story instead.}

\section{MESSAGE SHIFT}

FROM

Flexible work arrangements

are not a barrier to effective

leadership.
TO

Flexible work arrangements
help nurture and retain
effective leaders.

effective leaders.
Respectful relationships

education isn't about

teaching students radical

gender theory.

Respectful relationships
education helps students
question outdated gender
stereotypes.
stereotypes. 


\section{Our persuasive story}

In our testing, we uncovered a coherent and persuasive core narrative for gender equality that can be applied across issue areas - from equal pay and women's leadership, to sharing of housework and men's violence against women.

Importantly, this is a narrative that can both be used in the context of behaviour change campaigns and for building support for more systemic policy-oriented solutions.
Each element of our new narrative not only appeals strongly to supporters, but also to the majority of persuadables. Best of all, it is significantly more persuasive than the opposition narratives we tested.

Below we outline the core ingredients of our new narrative, before demonstrating examples of how they work in practice across topic areas.

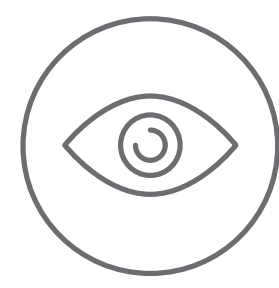

1. Vision

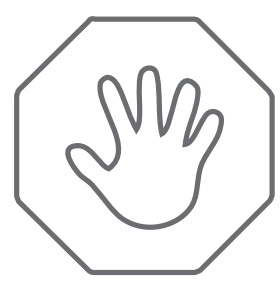

2. Barrier

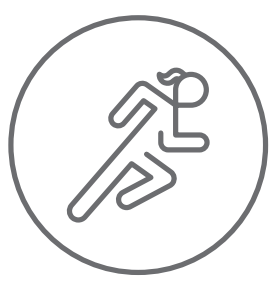

3. Action

\section{Vision}

To set a positive tone for our communications, it is important to start by articulating a valuesbased vision. This helps us frame the message in terms of shared values that appeal powerfully to both our supporters and persuadable audiences.
Core ingredients:

- Focus on the importance of equality and freedom to choose your own path in life.

- Remind your audience these values are broadly shared in our community.

\section{Example:}

"We all want to be respected as unique individuals with our own interests, skills and aspirations." 


\section{Barrier}

The barrier part of our narrative tells our audience what stands between us and the vision we seek. It establishes the problem and sets the stage for why our solutions are necessary.
Core ingredients:

- Focus on how different expectations, pressures and treatment of people based on their gender gets in the way of our vision.

- Point to specific examples of how these outdated norms lead to unequal outcomes for women and men.

Example:

"But too many people find their opportunities in life are shaped by outdated assumptions and are treated differently because of their gender. Women, in particular, face additional barriers in the workplace, where many employers continue to overlook them for senior roles. As a result, men are overrepresented as CEOs despite business outcomes being no better than those generated by business with women at the helm."

\section{Action}

Here is where we explain what can be done to remove the barrier that stands in our way. The solutions will vary depending on the issue but should always provide a clear role for our audience.
Core ingredients:

- Focus on how your solution will help challenge outdated norms and help affirm our shared values.

- Frame solutions as tools that help people do what they know is right (as opposed to top-down rules that force people to change).

- Point to success stories where possible to show the solution is both accepted and effective.

\section{Example:}

"Many leading businesses already use targets for women in senior roles to make sure the experiences and qualifications of female candidates are more seriously considered during recruitment and promotion decisions. By ensuring all large businesses across Victoria set similar targets, we can create more equal outcomes for all women across our state no matter where they work." 


\section{Words to use and lose}

When engaging with the public on a topic like gender equality, it is important to remember that the words we use as subject matter experts on a daily basis may not mean the same thing to our audience as they do to us. Thinking carefully about the language we use in public is therefore an important step to communicating clearly and persuasively.
Based on our testing, the following are suggestions for words and phrases that we should either use or lose when communicating with the public on the topic of gender equality.

\section{LOSE}

USE INSTEAD

$\begin{array}{ll}\text { Men and women } & \text { Everyone } \\ \text { - People }\end{array}$

Pay gap

- Pay discrimination

\section{Gender inequality}

Promoting gender equality

Masculinity
- Unfair assumptions, pressures and treatment of people based on gender

- Discrimination based on gender

- Gender stereotypes

- Outdated ideas about gender

- Encouraging more equal treatment and valuing of women in [sport/ politics/business/etc].

- Ensuring everyone is valued and treated as equals regardless of gender.

- Masculine stereotypes

- Gender stereotypes

- Old ideas about masculinity
WHY

Avoid unnecessarily reinforcing gender binaries when talking about things that apply equally to all genders. Exceptions to this would include situations in which it is important not to ignore the reality of inequalities between men, women and gender diverse people.

'Pay gap' shows that there's a difference in outcome but doesn't necessarily show it's unfair (the opposition would say women are worth (ess). 'Pay discrimination' puts focus on employers and their immoral behaviour rather than employees and their outcomes.

Focusing on unfair or immoral attitudes and behaviours drives significantly more support from persuadables than focusing on unequal outcomes alone (see tip \#2).

Since most people already agree with the principle of gender equality it doesn't need 'promoting'. Instead of using this vague phrase, be more specific about what you are doing to bring gender equality about in your context.

Many people assume masculinity simply means men. Referring to masculinity instead as a stereotype or an outdated set of ideas implies that it is both something undesirable and external to men. 


\section{Message examples}

There is no one right way to use our suggested story framework. Across different topic areas and communication channels you will need to vary the way you tell this story placing different emphasis on story elements or changing the order of elements altogether. A media release, for example, will call for a different structure and emphasis than a social media post or promotional video.
Below are some examples of how this story framework could be executed across different topic areas. These are intended as inspiration for your message crafting, rather than as the final word on how these topics should be communicated.

\section{Workplaces and Gender Equality Action Plans}

We all want to be respected as unique individuals with our own interests, skills and aspirations.

But too many people find their opportunities in life are limited by outdated ideas about gender. In workplaces, for example, many employers overlook women for senior roles based on assumptions about women's leadership skills.
Meanwhile, employers are less likely to grant flexible work hours to men wanting to take on more caring responsibilities at home.

One way to overcome these stereotypes is by ensuring all large employers develop gender equality action plans to help them monitor and act on gender-based discrimination.

\section{Parenting and respectful relationships}

We expect people to treat each other as equals no matter their gender.

But the reality is, too many of us expect different things from boys and girls, women and men, and we often treat them differently as a result - sometimes without even realising it.
These outdated ideas lead some men to think they are not only entitled to dominate women, but that we expect it of them. And too many use violence to maintain that control.

Raising our children as equals means freeing them from outdated stereotypes. Even the little things count, like letting all children play with both trucks and dolls.

\section{Relationships and housework}

Healthy relationships are about respecting each other as equals - and sharing the load when it comes to caring for kids and doing housework.

While a lot of things have changed over the decades, there is still more pressure on women to care for children and clean the home, even if they work full time.
These outdated expectations lock men and women into unequal roles that don't help any of us live the life we really want.

It's up to all of us, as families, employers, and governments, to give each other the support we need to challenge these outdated expectations and model more equal relationships for our children to follow.

\section{Community Sports Clubs}

Most people agree your gender should not get in the way of you leading the life you choose. Yet too often, women and girls who want to participate in community sport are not able to participate in the way they would like to due to outdated cultures, policies and practices or funding arrangements that prioritise the men's and boys' teams.
Thankfully, many clubs are realising the old way of doing things isn't working for women and girls and are looking for opportunities to change. By supporting these clubs to increase promotion, participation and leadership opportunities for women and girls and working with local government on developing equitable participation and facility allocation policies, we can ensure that everyone who wants to get involved in our sporting community is met with the welcoming, respectful and rewarding atmosphere they deserve. 


\section{VicHealth}

Victorian Health Promotion Foundation PO Box 154 Carlton South

Victoria 3053 Australia

$T+61396671333 F+61396671375$

vichealth@vichealth.vic.gov.au

vichealth.vic.gov.au

twitter.com/vichealth

facebook.com/vichealth

VicHealth is committed to health equity, which means levelling the playing field between people who can easily access good health and people who face barriers, to achieve the highest level of health for everyone.

VicHealth acknowledges the support of the Victorian Government.

(C) VicHealth

January 2021

https://doi.org/10.37309/2020.HP1009

\section{YICTORIA \\ State
Government}

VicHealth acknowledges the Traditional Custodians of the land. We pay our respects to all Elders past, present and future. 